\title{
An Adverse Role for Matrix Metalloproteinase 12 after Spinal Cord Injury in Mice
}

\author{
Jennifer E. A. Wells, ${ }^{1}$ Tiffany K. Rice, ${ }^{1}$ Robert K. Nuttall, ${ }^{3}$ Dylan R. Edwards, ${ }^{3}$ Hakima Zekki, ${ }^{4}$ Serge Rivest, ${ }^{4}$ \\ V. Wee Yong ${ }^{1,2}$ \\ Departments of ${ }^{1}$ Clinical Neurosciences and ${ }^{2}$ Oncology, Faculty of Medicine, University of Calgary, Calgary, Alberta T2N 4N1, Canada, ${ }^{3}$ School of Biological \\ Sciences, University of East Anglia, Norwich NR4 7TJ, United Kingdom, and ${ }^{4}$ Laboratory of Molecular Endocrinology and Department of Anatomy and \\ Physiology, Laval University, Quebec, Quebec G1V 4G2, Canada
}

We investigated the role of matrix metalloproteinases (MMPs) in acute spinal cord injury (SCI). Transcripts encoding 22 of the 23 known mammalian MMPs were measured in the mouse spinal cord at various time points after injury. Although there were significant changes in the expression levels of multiple MMPs, MMP-12 was increased 189-fold over normal levels, the highest of all MMPs examined. To evaluate the role of MMP-12 in SCI, spinal cord compression was performed in wild-type (WT) and MMP-12 null mice. Behavioral analyses were conducted for 4 weeks using the Basso-Beattie-Bresnahan (BBB) locomotor rating scale as well as the inclined plane test. The results show that MMP-12 null mice exhibited significantly improved functional recovery compared with WT controls. Twenty-eight days after injury, the BBB score in the MMP-12 group was 7, representing extensive movement of all three hindlimb joints, compared with 4 in the WT group, representing only slight movement of these joints. Furthermore, MMP-12 null mice showed recovery of hindlimb strength more rapidly than control mice, with significantly higher inclined plane scores on days 14 and 21 after SCI. Mechanistically, there was decreased permeability of the blood-spinal barrier and reduced microglial and macrophage density in MMP-12 null mice compared with WT controls. This is the first study to profile the expression patterns of a majority of the known MMPs after spinal cord compression. The data indicate that MMP-12 expression after spinal cord trauma is deleterious and contributes to the development of secondary injury in SCI.

Key words: metalloproteinase; trauma; spinal cord injury; neuroinflammation; recovery; microglia

\section{Introduction}

Spinal cord injury (SCI) is a leading cause of permanent disability in young adults, resulting in partial or complete loss of motor and sensory function below the lesion site. Currently, treatment options are limited, but significant advances have been made in understanding the pathophysiology of SCI. Although little can be done to prevent damage that occurs as a direct result of the trauma (primary injury), there is hope that the spread of damage that occurs in the days, weeks, and months after injury (secondary degeneration) can be abrogated or prevented. Evidence in the literature indicates that the sparing of as little as $10 \%$ of spinal cord axons from damage can have significant benefits on functional outcome (Eidelberg et al., 1977; Blight, 1983). Understanding the mechanisms involved in the development of secondary damage after spinal cord trauma is critical to the discovery of new therapeutic strategies to treat SCI.

Matrix metalloproteinases (MMPs) are a family of zincdependent endopeptidases capable of degrading all components of the extracellular matrix (ECM). As such, they have been shown

Received July 15, 2003; revised Aug. 21, 2003; accepted Sept. 12, 2003.

This study was supported by an operating grant from the Canadian Institutes of Health Research. We thank Yan Fan for skilled technical assistance and Fiona Yong for graphical expertise.

Correspondence should be addressed to Dr. V. Wee Yong, University of Calgary, 3330 Hospital Drive, Calgary, Alberta T2N 4N1, Canada. E-mail: vyong@ucalgary.ca.

Copyright $\odot 2003$ Society for Neuroscience 0270-6474/03/2310107-09\$15.00/0 to be critical in events requiring matrix remodeling, such as developmental processes and wound healing and repair throughout life (Yong et al., 2001). MMPs are now known to have many substrates in addition to ECM molecules (McCawley and Matrisian, 2001), and they are implicated in diverse functions, including the regulation of survival, signaling, angiogenesis, inflammation, and cell motility (Egeblad and Werb, 2002). Not surprisingly, therefore, the aberrant expression of several MMPs is correspondent with a number of disease pathologies, including cancer metastasis and CNS disorders such as multiple sclerosis (MS), stroke, human immunodeficiency virus dementia, and trauma (Yong et al., 2001).

Recently, the role of a single MMP member, MMP-9, has been examined in SCI. MMP-9 was found to be upregulated after a contusion injury, and this was correlated with a dysfunction in blood-spinal barrier integrity and inflammation (Noble et al., 2002). Furthermore, Noble et al. (2002) showed that functional recovery from SCI was significantly improved in MMP-9 null mice compared with wild-type (WT) controls. In brain trauma, it has been reported that motor outcomes (RotaRod test) at 1, 2, and $7 \mathrm{~d}$ were improved in MMP-9 null mice relative to WT animals (Wang et al., 2000). Because there are 23 mammalian MMP members, it remains to be determined whether more MMPs are upregulated in SCI and whether these play a more critical function in SCI. 
Table 1. Genes analyzed by quantitative TaqMan PCR

\begin{tabular}{|c|c|c|}
\hline Gene & Primer/probe & Sequence \\
\hline \multirow[t]{3}{*}{ TIMP-1 } & Forward primer & CATGGAAAGCCTCTGTGGATATG \\
\hline & Reverse primer & AAGCTGCAGGCACTGATGTG \\
\hline & Probe & CTCATCACGGGCCGCCTAAGGAAC \\
\hline \multirow[t]{3}{*}{ TIMP-2 } & Forward primer & CCAGAAGAAGAGCCTGAACCA \\
\hline & Reverse primer & GTCCATCCAGAGGCACTCATC \\
\hline & Probe & ACTCGCTGTCCCATGATCCCTTGC-TAMRA \\
\hline \multirow[t]{3}{*}{ TIMP-3 } & Forward primer & GGCCTCAATTACCGCTACCA \\
\hline & Reverse primer & CTGATAGCCAGGGTACCCAAAA \\
\hline & Probe & TGCTACTACTTGCCTTGTTTTGTGACCTCCA \\
\hline \multirow[t]{3}{*}{ TIMP-4 } & Forward primer & TGCAGAGGGAGAGCCTGAA \\
\hline & Reverse primer & GGTACATGGCACTGCATAGCA \\
\hline & Probe & CCACCAGAACTGTGGCTGCCAAATC \\
\hline \multirow[t]{3}{*}{ MMP-1a } & Forward primer & GTCTTTGAGGAGGAAGGCGATATT \\
\hline & Reverse primer & AGTTAGGTCCATCAAATGGGTTGTT \\
\hline & Probe & СTCTCCTTCCACAGAGGAGACCATGGTGA \\
\hline \multirow[t]{3}{*}{$M M P-16$} & Forward primer & TTTGAGGAGGAAGGCGATATTGT \\
\hline & Reverse primer & As MMP-1a \\
\hline & Probe & As MMP-1a \\
\hline \multirow[t]{3}{*}{$M M P-2$} & Forward primer & AACTACGATGATGACCGGAAGTG \\
\hline & Reverse primer & TGGCATGGCCGAACTCA \\
\hline & Probe & TCTGTCCTGACCAAGGATATAGCCTATTCCTCG \\
\hline \multirow[t]{3}{*}{$M M P-3$} & Forward primer & GGAAATCAGTTCTGGGCTATACGA \\
\hline & Reverse primer & TAGAAATGGCAGCATCGATCTTC \\
\hline & Probe & AGGTTATCCTAAAAGCATTCACACCCTGGGTCT \\
\hline \multirow[t]{3}{*}{ MMP-7 } & Forward primer & GCAGAATACTCACTAATGCCAAACA \\
\hline & Reverse primer & CCGAGGTAAGTCTGAAGTATAGGATACA \\
\hline & Probe & CCAAAATGGCATTCCAGAATTGTCACCTAC \\
\hline \multirow[t]{3}{*}{ MMP-8 } & Forward primer & GATTCAGAAGAAACGTGGACTCAA \\
\hline & Reverse primer & CATCAAGGCACCAGGATCAGT \\
\hline & Probe & CATGAATTTGGACATTCTTTGGGACTCTCTCAC \\
\hline \multirow[t]{3}{*}{ MMP-9 } & Forward primer & CGAACTTCGACACTGACAAGAAGT \\
\hline & Reverse primer & GCACGCTGGAATGATCTAAGC \\
\hline & Probe & TCTGTCCAGACCAAGGGTACAGCCTGTTC \\
\hline \multirow[t]{3}{*}{ MMP-10 } & Forward primer & CCTGATGTTGGTGGCTTCAGT \\
\hline & Reverse primer & CTGGTGTATAATTCACAATCCTGTAGGT \\
\hline & Probe & CCTTCCCAGGTTCGCCAAAATGGA \\
\hline \multirow[t]{3}{*}{ MMP-11 } & Forward primer & ATTGATGCTGCCTTCCAGGAT \\
\hline & Reverse primer & GGGCGAGGAAAGCCTTCTAG \\
\hline & Probe & TCCTTCGTGGCCATCTCTACTGGAAGTTTG \\
\hline \multirow[t]{3}{*}{ MMP-12 } & Forward primer & GAAACCCCCATCCTTGACAA \\
\hline & Reverse primer & TTCCACCAGAAGAACCAGTCTTTAA \\
\hline & Probe & AGTCCACCATCAACTTTCTGTCACCAAAGC \\
\hline \multirow[t]{3}{*}{ MMP-13 } & Forward primer & GGGCTCTGAATGGTTATGACATTC \\
\hline & Reverse primer & AGCGCTCAGTCTCTTCACCTCTT \\
\hline & Probe & AAGGTTATCCCAGAAAAATATCTGACCTGGGATTC \\
\hline \multirow[t]{3}{*}{ MMP-14 } & Forward primer & AGGAGACAGAGGTGATCATCATTG \\
\hline & Reverse primer & GTCCCATGGCGTCTGAAGA \\
\hline & Probe & CCTGCCGGTACTACTGCTGCTCCTG \\
\hline MMP-15 & Forward primer & ATCCCCTATGACCGCATTGAC \\
\hline & Reverse primer & СCCCTGCCAGACACTGATG \\
\hline & Probe & ACACAGCATGGAGACCCTGGCTACCC \\
\hline MMP-16 & Forward primer & GGCTACCTTCCACCGACTGA \\
\hline & Reverse primer & СTTCATCCAGTCGATTGTGTTTCT \\
\hline & Probe & CTGCAGAGACCATGCAGTCAGCTCTAGCT \\
\hline MMP-17 & Forward primer & GGCAGTATGTTCCTGCACTTCA \\
\hline & Reverse primer & GCTAGCACTGCCCTCAGGAT \\
\hline & Probe & CCTGTGGACCTCAGTCTCTGCCAAGG \\
\hline MMP-19 & Forward primer & GCCCATTTCCGGTCAGATG \\
\hline & Reverse primer & AGGGATCCTCCAGACCACAAC \\
\hline & Probe & CCACAAGGGCCCGTATGAAGCAGC \\
\hline MMP-20 & Forward primer & GATCAGGAGGATTAAGGAGCTACAAA \\
\hline & Reverse primer & GGCGGTAGTTAGCCACATCAG \\
\hline & Probe & CCAGAATACAATGAATGTGATCAAGAAGCCTCG \\
\hline
\end{tabular}

(Table continues)
Table 1. (Continues)

\begin{tabular}{lll}
\hline Gene & Primer/probe & Sequence \\
\hline MMP-21 & Forward primer & TCCAAAGAAGATGAGCCAAGTG \\
& Reverse primer & ACGCTGAATCGAGGTTCTG \\
& Probe & TTCCAGCAATAATGCCTCAAAACCACCC \\
MMP-23 & Forward primer & CAGACTGTTGACCATGTCGGTAA \\
& Reverse primer & GAAGGAAAGAACTCTGTATGTGAGGTT \\
& Probe & CCGCTACACGCTGACACCGGC \\
MMP-24 & Forward primer & TATCATGGCTCCCTCTACCAATAC \\
& Reverse primer & CTGCGGACGGGAGTGT \\
& Probe & CCAGCTGAGCCCTCTGGAGCCA \\
MMP-25 & Forward primer & TGGCTGTCTGGGCTACTGAA \\
& Reverse primer & GGTAGGCCGAGCAAAGTG \\
& Probe & AATTCTCAGTACCAGGAGCCTGACATCATTATCC \\
MMP-28 & Forward primer & CCACTTGGACAGAGAGGATCAGT \\
& Reverse primer & AAGCGTTTCTTACGCCTCATTT \\
& Probe & CTGCTTGCTGGACACCGAGCCAA \\
\hline
\end{tabular}

Sequences for the primers and probes (Mus spp.) are shown in $5^{\prime}$ to $3^{\prime}$ orientation; probes contain a carboxyfluoroscein fluorescent reporter on the $5^{\prime}$ end and a carboxytetramethylrhodamine quencher on the $3^{\prime}$ end.

We sought to understand the role of MMPs in SCI. Although others have focused on a single MMP, we have profiled the expression of virtually all known MMPs and the four endogenous tissue inhibitors of metalloproteinase (TIMPs) after spinal cord compression in mice. We found that the expression of MMP-12 mRNA was the most elevated of all the genes analyzed, and we have determined that mice lacking this protease have better recovery from SCI than WT controls. These results implicate a new pathophysiological member in the sequelae of adverse events in SCI and suggest that metalloproteinase inhibitors may have utility in SCI.

\section{Materials and Methods}

Subjects and surgical procedures. Male mice $\sim 3$ months of age were used in all studies. Except for experiments comparing MMP-12 ${ }^{-/-}$(null) mice and their WT controls, which were both on the 129/SvEv background, CD1 outbred mice (Charles River Laboratories, Montreal, Quebec, Canada) were used in the study. Surgery consisted of anesthetizing mice with a mixture of ketamine and xylazine $(200$ and $10 \mathrm{mg} / \mathrm{kg}$, i.p., respectively). Animals were subsequently immobilized in a stereotactic frame. An incision was made in the skin, and the muscle and tissue overlying the vertebral column was blunt-dissected away. Using the spiny process of $\mathrm{T} 2$ as a landmark, a laminectomy was performed at the level of T3-T4, and the spinal cord was exposed. A rigid hook was used to clear a path underneath the cord so a modified aneurysm clip with a closing force of $8 \mathrm{gm}$ could be applied (Wells et al., 2003). Extradural compression of the cord was achieved by allowing the clip to slam shut on the cord, producing mechanical trauma. The clip was maintained in position for $1 \mathrm{~min}$, producing damage that also had ischemic components. After injury, the clip was removed, and the wound was closed using a nylon suture. Mice recovered in a room maintained at $27^{\circ} \mathrm{C}$. Manual expression of the bladder was required twice daily, and the food and water were placed directly in the cage to allow ready access.

TaqMan PCR. TaqMan real-time PCR was used to profile MMP mRNA levels. Mice ( $n=4$ per group) were killed 1,2 , and $5 \mathrm{~d}$ after injury, and four mice served as uninjured controls. Spinal cords were removed; a $1 \mathrm{~cm}$ segment including the injury site was homogenized in TRIzol reagent; and total RNA was extracted as previously described (Rostworowski et al., 1997). One microgram of RNA was reverse-transcribed to make cDNA. Each reaction contained the equivalent of $5 \mathrm{ng}$ of reversetranscribed RNA. The $18 \mathrm{~S}$ ribosomal RNA gene was used as an endogenous internal control to account for differences in the extraction of original tissue and reverse transcription of total RNA. The method for TaqMan PCR has been detailed previously (Nuttall et al., 2003). Table 1 contains the TaqMan primer and probe sequences for mouse MMPs and TIMPs. 
In situ hybridization. CD-1 mice underwent spinal cord compression or served as uninjured controls. After survival times of $3 \mathrm{hr}$ or $5 \mathrm{~d}(n=4$ per group); animals were given an overdose of ketamine and xylazine intraperitoneally and were transcardially perfused with $0.9 \%$ cold saline followed by $4 \%$ paraformaldehyde in $0.1 \mathrm{~m}$ borax buffer. Spinal cords were removed, postfixed, and transferred to a solution containing $10 \%$ sucrose diluted in $4 \%$ paraformaldehyde-borax buffer overnight at $4^{\circ} \mathrm{C}$. Frozen spinal cords were mounted on a microtome (Reichert-Jung; Cambridge Instruments, Deerfield, IL) and cut into 20- $\mu \mathrm{m}$-thick longitudinal sections. Sections were placed in a cold cryoprotectant solution ( $0.05 \mathrm{M}$ sodium phosphate buffer, $\mathrm{pH} 7.3,30 \%$ ethylene glycol, and 20\% glycerol) and stored at $-20^{\circ} \mathrm{C}$. The sections were exposed at $4^{\circ} \mathrm{C}$ to $\mathrm{x}$-ray films (Eastman Kodak Co., Rochester, NY) for 24 hr, dipped into NTB2 nuclear emulsion (Kodak; diluted 1:1 with distilled water), and exposed for $8-15 \mathrm{~d}$ before being developed and counterstained with thionin $(0.25 \%)$.

The MMP-12 probe was purified from a plasmid (pGEM4) containing a 220 bp fragment (sequence 446-665) of MMP-12 (Pagenstecher et al., 1997). Linearization was achieved using EcoRI, and in vitro transcription with T7 (antisense) was performed. Subsequent probe processing was as previously described (Herx et al., 2000).

Immunohistochemistry was combined with in situ hybridization to determine the type of cells expressing the MMP-12 transcript after spinal cord trauma. Microglia/macrophages were immunostained as previously described (Herx et al., 2000) with an antibody raised against ionized calcium-binding adapter molecule 1 (Iba1). The Iba1 antibody, generously provided by Dr. Y. Imai (Department of Neurochemistry, National Institute of Neuroscience, Tokyo, Japan), recognizes both microglia and macrophages (Ito et al., 1998). In addition, immunostaining was performed for astrocytes using glial fibrillary acidic protein as well as von Willibrand Factor, a marker for endothelial cells. After reaction with diaminobenzidine for visualization of the product, sections were rinsed in potassium-supplemented PBS, mounted onto gelatin- and poly-Llysine-coated slides, desiccated under a vacuum for $30 \mathrm{~min}$, fixed in $4 \%$ paraformaldehyde for $20 \mathrm{~min}$, and digested by proteinase $\mathrm{K}(10 \mu \mathrm{g} / \mathrm{ml}$ in $100 \mathrm{~mm}$ Tris- $\mathrm{HCl}, \mathrm{pH} 8.0$, and $50 \mathrm{~mm}$ EDTA, $\mathrm{pH} 8.0$ ) at $37^{\circ} \mathrm{C}$ for $25 \mathrm{~min}$. Hybridization of the MMP-12 probe with tissue mRNA was then performed as described above.

Behavioral study. To investigate the role of MMP-12 after spinal cord trauma, compression injury was induced in MMP-12 null and WT mice as described above. MMP-12 null mice were obtained from the laboratory of Steve Shapiro (Brigham and Women's Hospital, Harvard Medical School, Boston, MA) (Shipley et al., 1996), and a breeding colony was established in the animal care facility at the University of Calgary. Groups consisted of 12 MMP-12 null mice and 10 WT mice. After surgery, animals were singly housed in a temperature-controlled environment $\left(27^{\circ} \mathrm{C}\right)$ and maintained for $28 \mathrm{~d}$ so behavioral assessments of recovery of hindlimb function and strength could be made.

Recovery of hindlimb function was assessed using the Basso-BeattieBresnahan (BBB) motor rating scale (Basso et al., 1995). This is a 22point scale (scores $0-21$ ) that systematically and logically follows recovery of hindlimb function from a score of 0 , indicative of no observed hindlimb movements, to a score of 21 , representative of a normal ambulating rodent. Testing procedures were as follows. Briefly, $5 \mathrm{~d}$ before surgery, animals were exposed to the open field arena for 5 min durations so they could be acclimated to the test apparatus and thereby reduce the stress response as a confounding variable during postoperative testing. On the last day before surgery, all animals had a score of 21 . The first test session began $3 \mathrm{~d}$ after injury and continued twice weekly throughout the survival period. Test sessions were $4 \mathrm{~min}$ in duration, and scores were obtained from 1 or 2 blinded observers.

Recovery of hindlimb strength was assessed once weekly beginning on day 7 after injury using the inclined plane task (Fehlings and Tator, 1992). Briefly, animals were placed on an inclined plane, and the angle of incline was gradually increased by $5^{\circ}$ increments. The maximum angle at which the animal could maintain its position for $5 \mathrm{sec}$ constituted the inclined plane score.

Histological analysis. A second group of mice $(n=30)$ underwent compression surgery followed by $5 \mathrm{~d}$ survival to assess histological changes early after injury. The time point of $5 \mathrm{~d}$ was chosen because this corresponds to the time of the maximum increase in MMP-12 mRNA that was observed. Spinal cords were removed and postfixed in $10 \%$ neutral buffered formalin. Ten of the cords (five WT and five null) were placed in a $20 \%$ sucrose solution overnight and then frozen. Fifteenmicrometer-thick sections were cut, mounted on glass slides, and stained with IgG antibody for assessment of blood-spinal barrier integrity (Herx and Yong, 2001). Briefly, sections were incubated with biotinylated mouse IgG overnight at $4^{\circ} \mathrm{C}$ followed by $\mathrm{ABC}$ reagent (Vectastain; Vector Laboratories, Burlingame, CA) for $30 \mathrm{~min}$ at room temperature. Positive staining was visualized using diaminobenzidine (DAB), which produces a brown reaction product. All sections were stained simultaneously, and the $\mathrm{DAB}$ reaction was precisely timed so comparisons could be made. A representative section from each of 11 mice was chosen and photographed, and an observer blind to treatment groups assessed the $11 \mathrm{sec}-$ tions for the degree of IgG staining; sections were ranked in order of 1-11 with 11 indicating the most intense staining and 1 the least.

Remaining cords were embedded in paraffin, and $6 \mu \mathrm{m}$ sections cut. Serial sections were stained for Iba1 and neutrophils. For Iba1 staining, which does not differentiate between microglia and macrophages (Ito et al., 1998), sections were rehydrated and rinsed with PBS followed by antigen retrieval using $10 \mathrm{~mm}$ sodium citrate buffer, $\mathrm{pH}$ 6.5. The primary antibody was diluted 1:500, and sections were incubated overnight at $4^{\circ} \mathrm{C}$. Biotinylated anti-rabbit IgG was used for the secondary antibody, and staining was visualized with $\mathrm{ABC}$ using $\mathrm{DAB}$ as the substrate. Sections were analyzed blind for the degree of microglial/macrophage activation, determined by the morphology and density of the Ibal-labeled cells. Normal resting or quiescent microglia exhibit a distinct morphology, with many ramified processes projecting from the cell body. When activated, these processes begin to retract and thicken, and the microglia take on a more ameboid, macrophage-like appearance (Leong and Ling, 1992; Dusart and Schwab, 1994; Streit et al., 1998); in this regard, and because most markers cannot differentiate between microglia and macrophages, they are usually referred to as mononuclear phagocytes or simply microglia/macrophages. Ibal-stained sections were scored for microglia/macrophage activation using a scale of $0-4$ in which 0 was normal cord and 4 was the presence of highly activated microglia/macrophages. Considerations were made for the size, shape, and relative density of Iba1-labeled cells.

Neutrophils were visualized using chloroacetate esterase stain and counterstained with hematoxylin, and the numbers of positively stained cells displaying multilobed nuclei were counted blind in sections from WT and MMP-12 null mice.

\section{Results \\ Multiple MMPs are upregulated in SCI, and MMP-12 is the most abundant}

The expression of several MMPs transcript (MMP-2, -3, -7, -10, $-11,-12,-13,-19$, and -20 ) was found to be upregulated after spinal cord trauma (Fig. 1). This was time-dependent, in that many of the MMPs were upregulated $24 \mathrm{hr}$ after injury (MMP-3, $-7,-10,-11,19$, and -20$)$, whereas the increased expression of other MMPs (MMP-2, -12, and -13) was delayed until $5 \mathrm{~d}$. We noted an increase in MMP-9 at $24 \mathrm{hr}$ as described by others for SCI (Noble et al., 2002), but this did not reach statistical significance (one-way ANOVA). A significant decrease was found in the expression of two MMPs after SCI: MMP-23 and -24. Transcripts for MMP-1a and -1b were not detectable in any of the tissue samples.

Because the TaqMan analysis is quantitative over a 6 log scale of mRNA copies (Nuttall et al., 2003), we elucidated the fold change of each MMP member at the 1,2, and $5 \mathrm{~d}$ time points relative to the normal control values. The most marked upregulation was for MMP-12, which increased 189-fold from basal levels. The elevation of MMP-12 was still evident at $14 \mathrm{~d}$ after SCI, as determined using an RNase protection assay (data not shown). Analyses of TIMPs by TaqMan PCR show that there was a 
significant elevation in the expression of TIMP-1. This was maximal $24 \mathrm{hr}$ after injury and remained significantly elevated at $5 \mathrm{~d}$ (data not shown). TIMP-2, -3 , and -4 were not altered from controls.

MMP-12 is expressed by cells of the mononuclear phagocyte lineage In situ hybridization for the MMP-12 transcript was used to localize its expression in the injured spinal cord tissue (Fig. 2). In uninjured controls (Fig. $2 \mathrm{~A}$ ) or at $3 \mathrm{hr}$ after SCI (Fig. 2B), the MMP-12 transcript was not detected. In contrast, there was a prominent increase in MMP-12 mRNA expression in the lesion epicenter $5 \mathrm{~d}$ after injury (Fig. 2C,D).

The source of MMP-12 after injury was likely cells of the mononuclear phagocyte lineage, i.e., microglia or macrophages, because MMP-12 silver grains were colocalized to Iba1-stained cells (Fig. 2E) but did not colocalize with astrocytes (Fig. $2 F$ ) or endothelial cells (data not shown). We noted that not all Iba1-positive cells were positive for MMP-12 mRNA (Fig. 2E, arrowheads).

\section{MMP-12 null mice are less impaired after SCI than WT mice}

All mice exhibited weight loss as a result of the SCI and did not return to original weight for the duration of the study. However, there were no significant differences in the weights of the mice from the MMP-12 null and WT groups at the beginning or throughout the experiment. All mice received subcutaneous injections of a lactated Ringer's solution after bladder squeezing on each behavioral test day to prevent dehydration.

Spinal cord compression resulted in hindlimb paralysis, with both groups receiving similar average BBB scores at day 3 after injury of 1 and 1.6 (MMP-12 null and WT, respectively), indicative of slight movements of 1 or 2 hindlimb joints. Both groups exhibited gradual recovery in hindlimb function as reflected in the higher scores obtained on subsequent test days. Repeated measures ANOVA revealed a significant treatment effect $(F=5.681 ; p<0.05)$, day effect $(F=42.807 ; p<0.001)$, and treatment-by-day interaction $(F=3.946 ; p<0.05)$, where MMP-12 null animals exhibited significant recovery in hindlimb function compared with WT mice (Fig. 3). Subsequent independent $t$ tests revealed that hindlimb recovery in the MMP-12 null mice was significantly different from that of WT mice on day 14 $(p<0.05)$, with MMP-12 null mice demonstrating higher scores. The scores were statistically different throughout the remaining survival period, with MMP-12 null mice receiving a final average score of 7 , indicative of extensive movement of all three hindlimb joints, compared with a score of 4.2 (slight movement of all hindlimb joints) in the WT group $(p<0.01)$. It is impor-

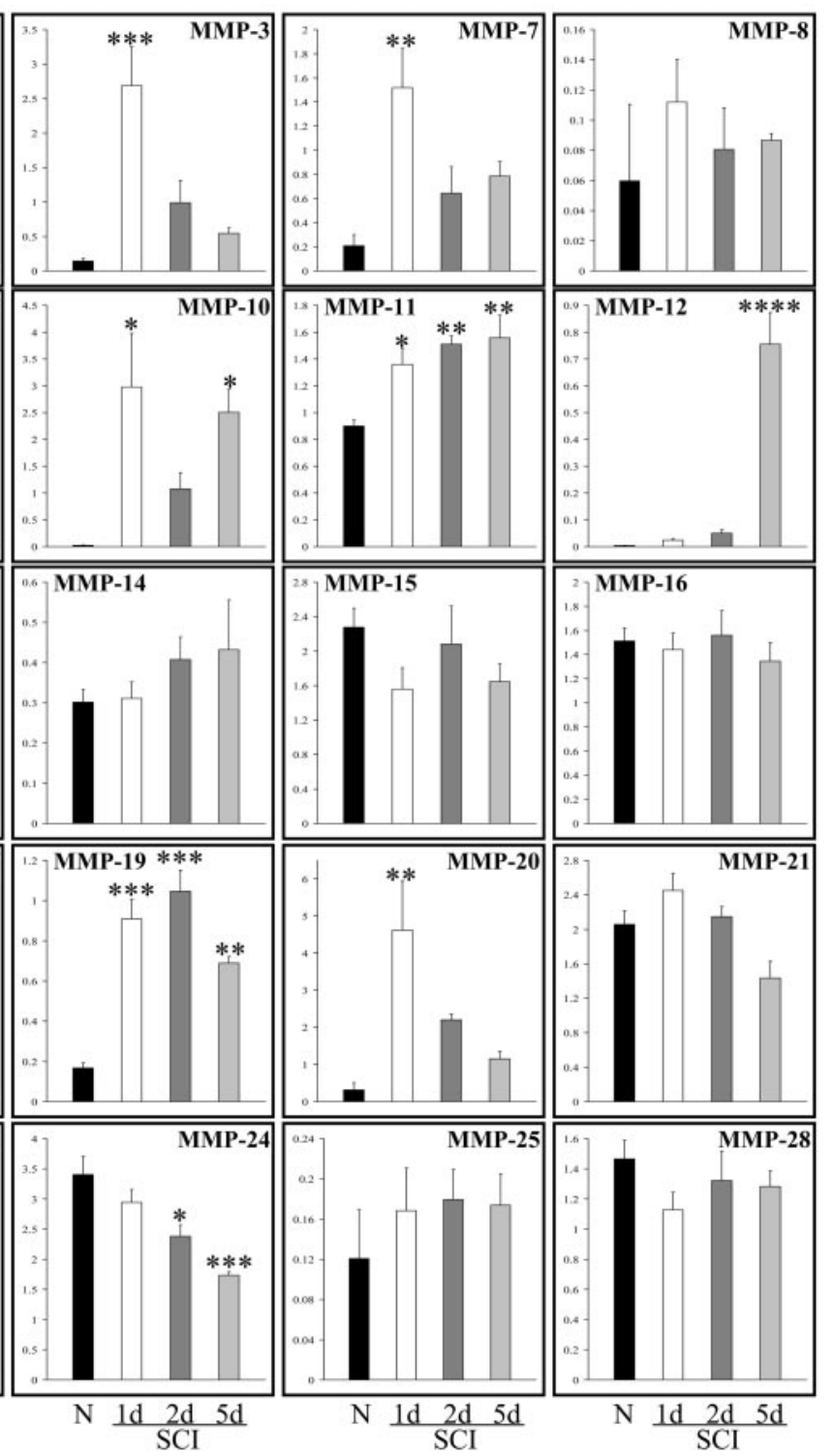

Figure 1. Expression levels of multiple MMPs are altered after spinal cord injury. Real-time TaqMan PCR revealed that the expression of several MMPs was altered after spinal cord compression. Several of the MMPs were upregulated $24 \mathrm{hr}$ after injury, including MMP-3, -7, -10,-11, -19, and -20, whereas the expression of other MMPs (MMP- $2,-12,-13$ ) was delayed until $5 \mathrm{~d}$. Furthermore, a significant decrease was found in the expression of two MMPs analyzed: MMP-23 and -24. MMP-27 was not analyzed because the murine gene sequence was not known at the time of the determinations. ${ }^{*} p<0.05$; ${ }^{* *} p<0.01$; ${ }^{* * *} p<$ $0.001 ; * * * 0<0.0001$, compared with normal animals.

tant to note that 5 of 10 MMP-12 null mice had achieved scores of $\geq 7$, and 4 of 10 had recovered the ability to support weight on their hindlimbs. This is in contrast to the WT animals, of which 9 of 10 had scores of $<7$, and only 1 mouse had the ability to support weight. This magnitude of difference in behavioral scores obtained between the two groups could be extremely important if translated to the clinical context of human SCI.

Using the inclined plane test, there was no difference in hindlimb strength between the groups 1 week after compression injury (Fig. 4). However, MMP-12 null mice demonstrated recovery of hindlimb strength earlier after injury, having significantly higher scores on the inclined plane task on days 14 and 21 after injury $(p<0.05)$.

Overall, MMP-12 null mice have better functional recovery from SCI than WT mice, indicating a detrimental role for MMP-12 in CNS trauma. 

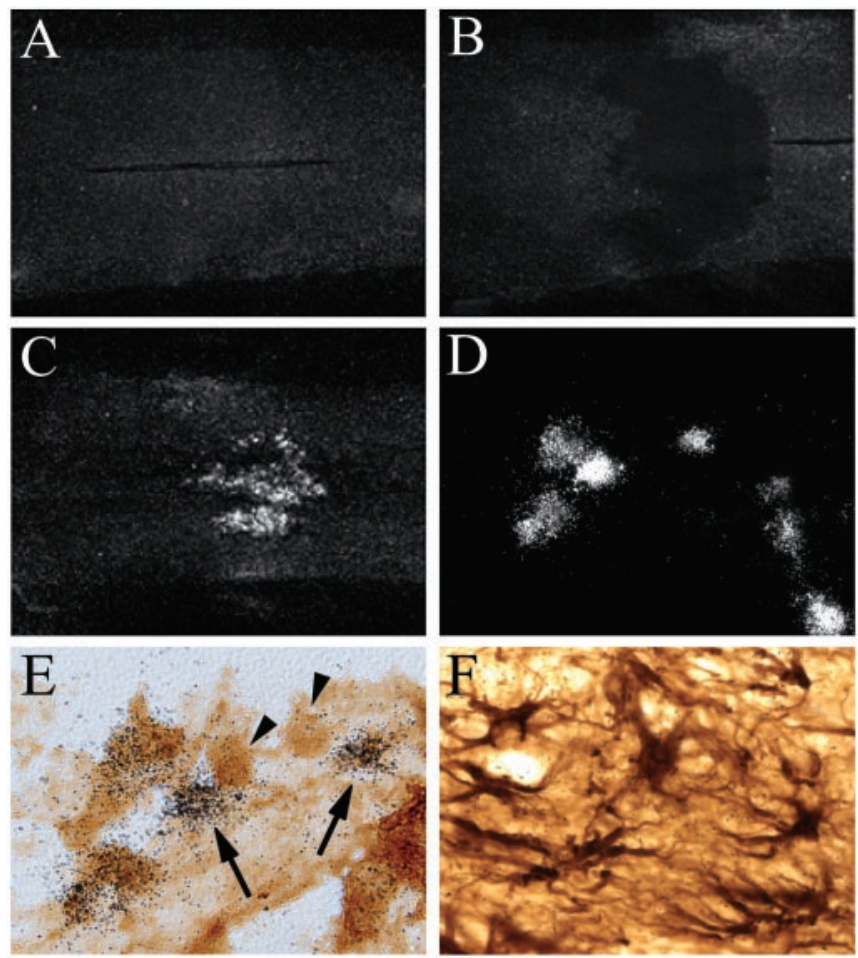

Figure 2. Microglia/macrophages are sources of MMP-12. In situ hybridization was performed using a probe for MMP-12 in spinal cord from a normal animal $(A), 3 \mathrm{hr}$ after injury $(B)$, and $5 \mathrm{~d}$ after injury (C). MMP-12 mRNA is not detected in normal tissue but is clearly upregulated within the lesion epicenter $5 \mathrm{~d}$ after injury. $D$, A higher magnification $(D)$ reveals the cellular localization of MMP-12 transcript. Immunohistochemistry for lba1 was combined with in situ hybridization using a probe for MMP-12 (E). The arrows indicate that lba-1-positive cells (macrophages or microglia) are the sources of the MMP-12 transcript; however, not all Iba1labeled cells (arrowheads) are positive for MMP-12 mRNA. Double labeling for glial fibrillary acidic protein and MMP-12 mRNA shows that astrocytes are not a source of MMP-12 after $\mathrm{SCl}(F)$.

\section{Mechanisms of MMP-12 in SCI}

MMPs are implicated in the disruption of the blood-brain barrier (Lo et al., 2002; Rosenberg, 2002). Thus, $5 \mathrm{~d}$ after spinal cord compression, tissue from both groups (six WT and five MMP-12 null mice) was assessed for blood spinal integrity using IgG leakage into the CNS parenchyma as an indicator. A blinded rank order analysis from 1 to 11 ( 11 being most extensive) was used for the 11 animals, and this showed that a majority of WT mice displayed more disruption of the blood-spinal barrier compared with MMP-12 null mice ( $p<0.05$; Fig. 5).

Because microglia activation and macrophage migration into the CNS are common occurrences in CNS trauma, and because MMP-12 has been implicated in the transmigration of macrophages into tissues (Hautamaki et al., 1997; Lanone et al., 2002), we used Ibal immunoreactivity to address the status of these mononuclear phagocytes in SCI. Preliminary analyses revealed that the number of Iba1-positive cells was comparable between WT and MMP-12 null mice in the uninjured state (Fig. 6A,D). On injury, there was activation and recruitment of mononuclear phagocytes in WT mice, as evident by the increased density of Iba1-stained cells and by their more ameboid morphology (Fig. $6 \mathrm{~B} ; p<0.05$, Mann-Whitney $U$ test). In contrast, although MMP-12 null mice showed evidence of microglial activation, as denoted by the fewer processes of some Iba1-stained cells, some microglia still retained the morphology of resting cells with well defined, thin, ramified processes (Fig. 6E).

Comparisons of the cell density of Iba1-positive elements in-

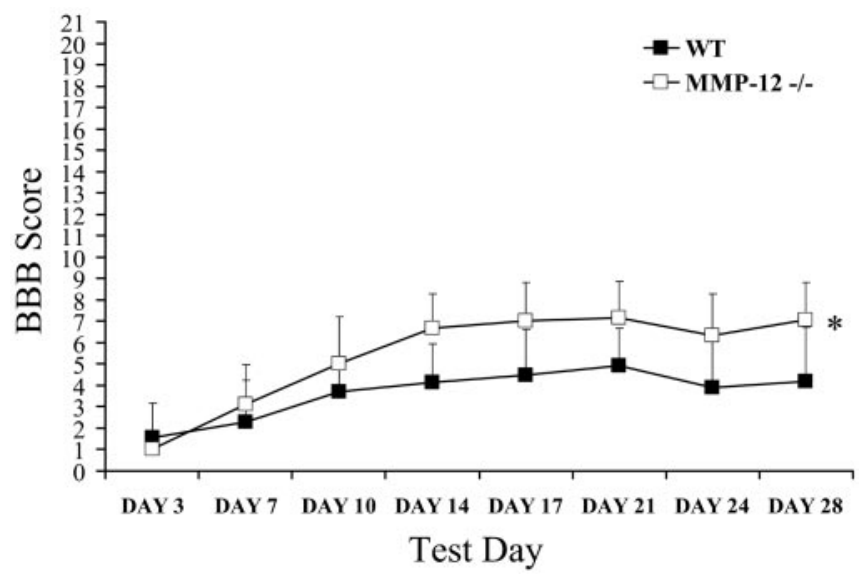

Figure 3. Improved hindlimb motility is found in MMP-12 null mice after $\mathrm{SCl}$ relative to wild-type animals. Before surgery, all animals had a score of 21, indicative of a normal ambulating rodent. Spinal cord compression resulted in hindlimb paralysis, with both WT $(n=10)$ and MMP-12 null ( $n=12$ ) groups receiving similar average scores at day 3 after injury. Both groups exhibited gradual recovery in hindlimb function over subsequent test days. Repeated measures revealed a significant treatment effect $\left({ }^{*} p<0.05\right.$ ), with MMP-12 null mice demonstrating greater recovery in hindlimb movements. Unpaired $t$ tests performed on each test day indicate that a separation occurs at day 14 after injury, with MMP-12 null mice exhibiting significantly higher scores $(p<0.01)$. This superior recovery continued throughout the survival period, with MMP-12 null mice receiving a final average score of 7 , indicative of extensive movement of all three hindlimb joints, compared with a score of 4.2 (slight movement of all hindlimb joints) in the WT group ( $p<0.01)$.

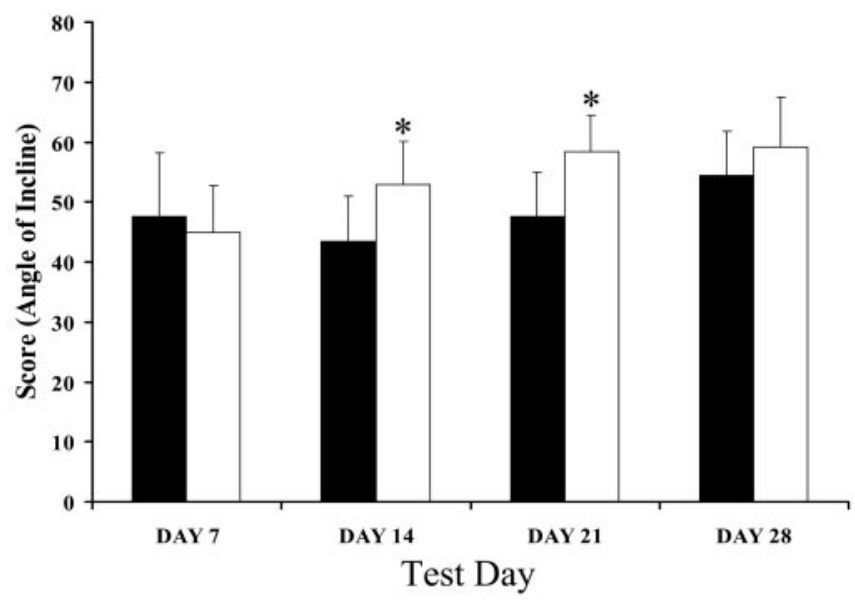

Figure 4. MMP-12 null mice recover hindlimb strength earlier than wild-type animals. One week after compression injury, there was no difference in hindlimb strength between the groups. However, MMP-12 null mice $(n=12)$ demonstrated recovery of hindlimb strength earlier after injury, having significantly higher scores on the inclined plane task on days 14 and 21 after injury $(p<0.05)$ compared with WT controls $(n=10)$. However, this difference was not maintained because day 28 scores were not significantly different.

dicated that there were less mononuclear phagocytes in MMP-12 null mice compared with WT animals after SCI (Fig. 6B,E). Besides the decreased microglia activation in MMP-12 null mice noted above, the lower density of Iba1-positive cells could also be the result of decreased influx of macrophages into the CNS of MMP-12 null mice. To address this, we analyzed tissue apposed to the area of injury, where rounded macrophages could be readily found in WT mice. Such comparisons showed that, although there was abundant Ibal rounded cells reminiscent of macrophages in WT mice (Fig. 6C), this was decreased in frequency in MMP-12 null mice (Fig. $6 F$ ). 


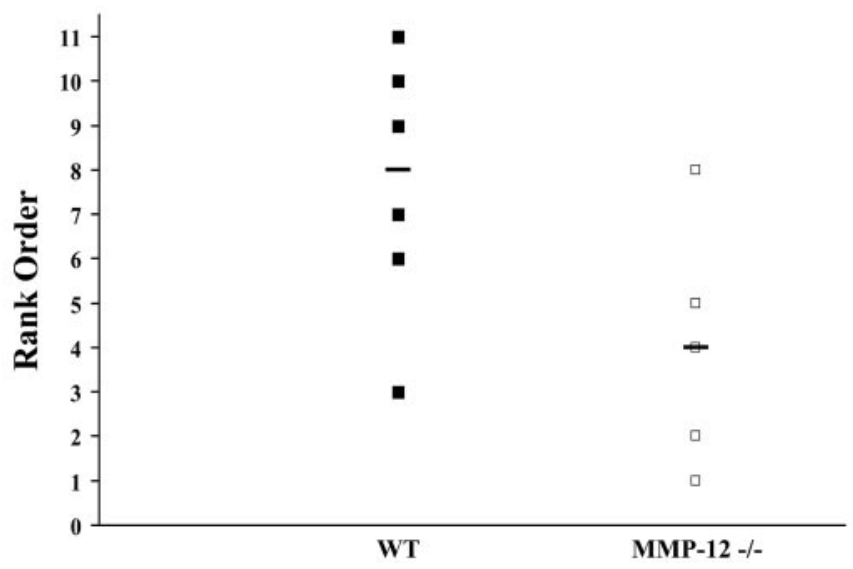

Figure 5. Blood-spinal barrier permeability is reduced in MMP-12 null mice. Blood-spinal barrier integrity was assessed using lgG immunostaining. Blinded analysis of a representative section from each of 11 mice used a ranking system in which 11 was the most permeable and 1 was the least permeable. There was a significant reduction in blood-spinal barrier disruption in MMP-12 null mice compared with WT controls $(p<0.05)$. The black line represents the median score for the groups.

Collectively, the data indicate that, although WT mice had microglia activation and influx of macrophages after SCI, this mononuclear phagocyte activation and density was significantly reduced in tissue adjacent to the lesion epicenter of MMP-12 null mice $(p<0.05$; Fig. $6 G)$.

\section{Discussion}

Numerous studies have demonstrated increases in MMPs in various CNS pathologies, and the temporal and spatial expression of the different MMPs may vary depending on the particular cell types producing them as well as on the type of insult (Hartung and Kieseier, 2000; Yong et al., 2001; Rosenberg, 2002). The most studied MMPs have been the gelatinase subfamily, MMP-2 and -9 , in large part because of their relative ease of detection using the method of gelatin zymography. The focus on MMP-2 and -9, however, minimizes the possibility that other MMP members may be more crucial as determinants of outcome after injury. In this context, the current study is the first to examine the profile of a majority of the MMP family members after spinal cord trauma. Twenty-two of the 23 known MMPs were analyzed. We found alterations in RNA levels of several MMPs. Interestingly, the timing of expression of these MMPs was variable, with some MMPs being increased within the first $24 \mathrm{hr}$, whereas others were not expressed until $5 \mathrm{~d}$ after injury. This different temporal expression is likely attributable to the various sources of individual MMPs being recruited and activated at the injury site at specific periods; neural cells as well as infiltrating macrophages and lymphocytes all have been shown to express MMPs (Rosenberg, 2002).

As previously mentioned, MMP-9 was reported to be increased after SCI and was shown to contribute to the development of secondary injury in mice (Noble et al., 2002). Although we found a trend toward an increase of MMP-9 (approximately twofold at $24 \mathrm{hr}$ after SCI), this did not reach statistical significance by ANOVA of all groups (normal, 24 and $48 \mathrm{hr}$ and $5 \mathrm{~d}$ after $\mathrm{SCI})$. However, an independent $t$ test comparing controls with SCI at $24 \mathrm{hr}$ did reach significance $(p<0.05)$, supporting the observation of Noble et al. (2002) that MMP-9 is elevated in SCI. Nonetheless, our results would indicate that other MMPs may be more important in SCI.

The most prominent change in MMP expression after SCI was for MMP-12. The MMP-12 transcript was increased 189-fold over normal levels at $5 \mathrm{~d}$, and that level remained high for at least 2 weeks, as seen in RNase protection assays (data not shown). In situ hybridization studies revealed that the MMP-12 transcript was localized to the lesion epicenter at $5 \mathrm{~d}$ after injury, and immunohistochemistry for Iba1, a marker for microglia and macrophages, indicated that cells of this lineage were responsible for producing MMP-12. Previous studies of SCI have documented an increase in macrophage infiltration with peak elevation of 3-7 d after injury (Dusart and Schwab, 1994); this time frame corresponds with what we have observed here. Also, other studies have reported that macrophages are a tremendous source of MMP-12 (Banda and Werb, 1981; Shapiro et al., 1993).

Before this study, the functional significance of MMP-12 in SCI had not been addressed. MMP-12 has been studied in other diseases, notably emphysema (Hautamaki et al., 1997; Horton et al., 1999) and abdominal aortic aneurysms (Curci et al., 1998), in which the overexpression of MMP-12 by macrophages leads to tissue destruction and formation of fibrosis. Recently, MMP-12 was studied in CNS pathology, including MS (Vos et al., 2003) and stroke (Power et al., 2003). With respect to MS, Vos et al. (2003) showed that a high number of MMP-12-positive phagocytic macrophages were present in lesions but not in control tissue. In an animal model of intracerebral hemorrhage, Power et al. (2003) demonstrated that the reduction of MMP-12 resulted in improved neurobehavioral outcomes. Although both papers implied that MMP-12 overexpression contributes to disease pathology, our current study provides strong evidence that MMP-12 expression is detrimental after SCI.

What are the mechanisms by which MMP-12 is harmful in SCI? First, we observed reduced blood-spinal barrier permeability in the MMP-12 null mice compared with WT mice, suggesting that MMP-12 activity impairs the integrity of the blood-spinal barrier. Several papers have reported a functional role for MMP-9 in the disruption of the blood-brain barrier (Lo et al., 2002; Noble et al., 2002; Rosenberg, 2002), and MMP-12 may now be added to this list. A second potential mechanism of MMP-12 in SCI is its role in the infiltration of macrophages into the injured CNS because macrophage migration has been correlated with expression of MMP-12 (Shipley et al., 1996; Hautamaki et al., 1997; Lanone et al., 2002) Infiltrated macrophages may be harmful because the reduction of macrophage infiltration resulted in significant recovery from SCI (Giulian and Robertson, 1990; Blight, 1994; Popovich et al., 1999; Mabon et al., 2000). Thus, the lack of MMP-12 in SCI may reduce the influx of macrophages and their toxic potential. This contention is borne out by the decreased frequency of Iba1-stained rounded cells, likely macrophages, in the vicinity of the injury site in MMP-12 null versus WT animals (Fig. 6C,F). This decreased macrophage infiltration is rather selective because the incidence of neutrophils in SCI is not different between MMP-12 null and WT mice (data not shown); neutrophil immigration appears to be a function of MMP-9 activity in some conditions (D'Haese et al., 2000).

A third mechanism by which MMP-12 may contribute to SCI pathophysiology is its mechanism within the CNS. Although we have no evidence of MMP-12 having direct central activity, in its presence, more microglia cells are activated (Fig, 6B). Thus, MMP-12 could be activating, either directly or indirectly, microglia cells. Microglia are the endogenous inflammatory cells of the CNS, and they respond rapidly after trauma (Morioka et al., 1991; Kreutzberg, 1996). Activated microglia are known to produce various toxic molecules, such as free radicals (Rogove and Tsirka, 1998), which can contribute to injury, and they also pro- 

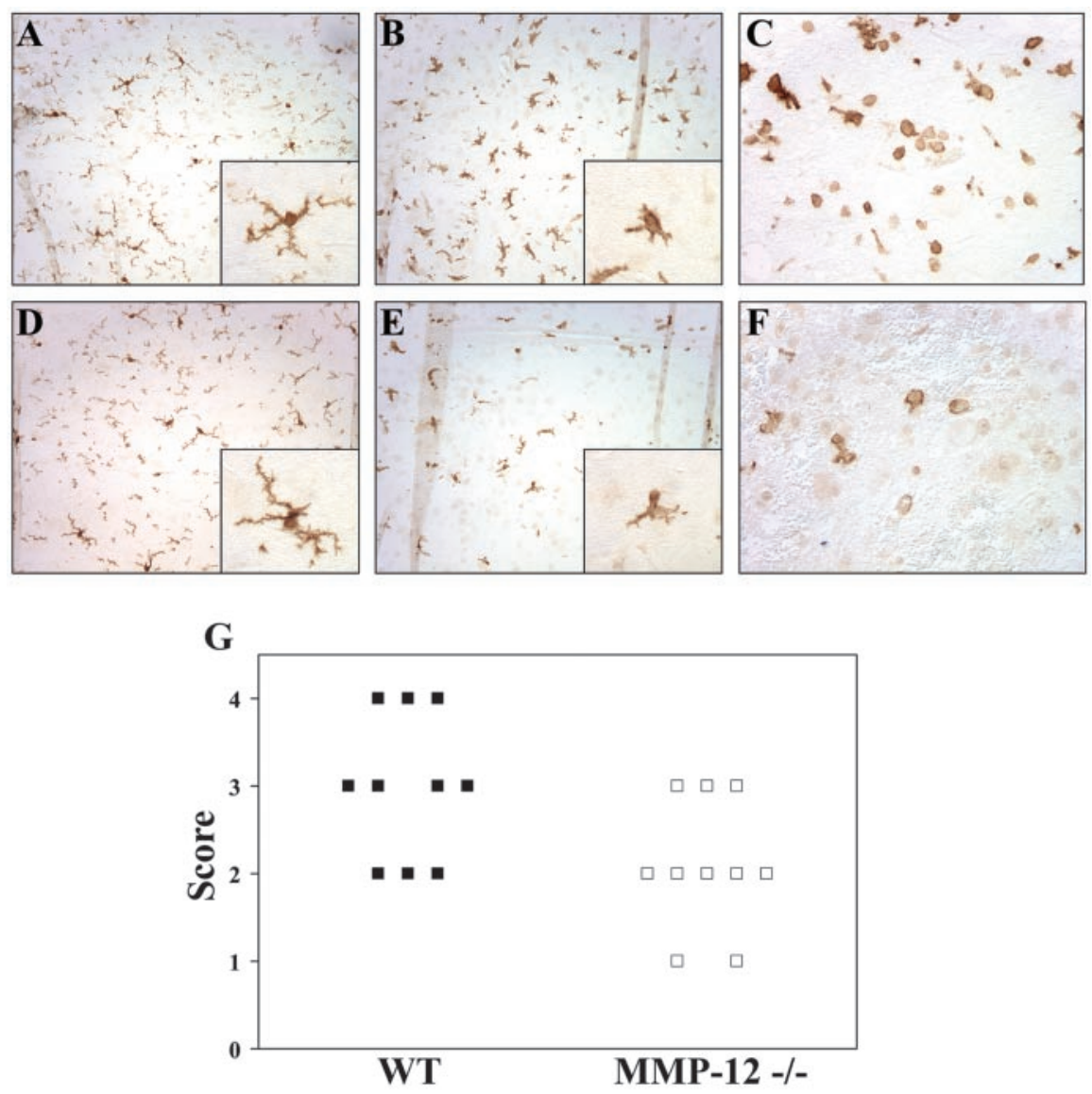

Figure 6. Microglia/macrophage activation and infiltration is reduced in MMP-12 null mice. Mononuclear phagocytes (microglia/macrophages) were visualized using Iba1. Blinded analysis of tissue sections revealed significant differences in the morphology and density of these cells between WT and MMP- 12 null mice $(G ; p<0.05)$. $A, D$, Representative sections from normal WT and MMP-12-deficient mice, respectively, demonstrating that there are no obvious differences in microglial staining in normal uninjured spinal cord tissue. $B, E$, Representative sections from WT and MMP- 12 null mice, respectively, $5 \mathrm{~d}$ after spinal cord compression. Note that in tissue adjacent to the lesion, there was increased density of cells in the WT tissue, as well as a more amoeboid morphology characteristic of activation $(B)$. In contrast, in MMP-12 null mice $(E)$, the density of microglial/macrophages was reduced, and many microglia, whereas demonstrating morphological changes indicative of activation (i.e., shortened and thickened processes; inset), did not progress as much as in WT animals ( $B$, inset). Insets in $A, B, D$, and $E$ are higher magnifications of representative microglia at rest $(A, D)$ and after trauma $(B, E) \cdot \ln C$ and $F$, which are lba1-stained rounded cells apposed to the lesion site (likely macrophages), there was decreased density in MMP-12 null mice compared with the WT animals.

duce various cytokines (e.g., interleukin $1 \beta$ and tumor necrosis factor $\alpha$ ) and proteases, which regulate and maintain an inflammatory response (Giulian and Corpuz, 1993; Giulian and Vaca, 1993; Rothwell et al., 1996; Kim and Ko, 1998). Furthermore, previous in vivo and in vitro experiments have correlated the activation of microglia to ischemic and excitotoxic neuronal death (Giulian and Corpuz, 1993; Giulian and Vaca, 1993; Kim and Ko, 1998; Rogove and Tsirka, 1998; Yrjanheikki et al., 1998, 1999), and parenchymal microglia have been reported to contribute to the delayed secondary enlargement of ischemic lesions (Giulian and Vaca, 1993; Dirnagl et al., 1999).

Finally, it remains to be determined whether MMP-12 is directly toxic when upregulated within the CNS. Some MMPs have been shown to be directly cytotoxic in vitro (Vos et al., 2000; Johnston et al., 2001), and this may be the case for MMP-12 as well. Alternatively, MMP-12 may be important for macrophage infiltration into the CNS parenchyma, and, once there, the cells produce a myriad of other harmful molecules (described above), which subsequently potentiate tissue destruction.

It is relevant to emphasize that although there was a significant reduction in both macrophage infiltration and microglial activation in the MMP-12 null mice, the responses were not completely abolished. This may be important because several aspects of inflammation are believed to be beneficial after injury. For instance, although several papers suggest a detrimental role of macrophages in SCI (Giulian and Robertson, 1990; Blight, 1994; Popovich et al., 1999; Mabon et al., 2000), macrophages may also facilitate recovery (Guth et al., 1994; Rapalino et al., 1998; Batchelor et al., 1999). Also, the implantation of activated macrophages into the lesion site after SCI in rats has resulted in significant recovery (Rapalino et al., 1998). Macrophages are capable of producing both toxic molecules (Giulian et al., 1993) and beneficial ones (i.e., growth factors; Batchelor et al., 1999). It may be postulated that too much macrophage infiltration is detrimental, whereas some degree is required for appropriate clearance of injury debris and recovery. Similarly, there is evidence that microglia may also exert beneficial roles after injury. In vitro studies have revealed that media from microglial cultures promote survival and differentiation of various neuronal cultures (Nagata et al., 1993; Jonakait et al., 1996). Other studies have demonstrated that thrombospondin derived from microglia promotes neurite growth (O'Shea et al., 1991; Nagata et al., 1993; Chamak et al., 1994; Arber and Caroni, 1995; Jonakait et al., 1996). Furthermore, recent in vivo work has shown that the implantation of cultured microglial cells into spinal cord lesions also enhanced neurite outgrowth (Rabchevsky and Streit, 1997).

The question of whether MMP-12 protease amplifies additional secondary damage or retards endogenous recovery has not been definitively answered in these experiments. Analysis of gross lesion sizes at 5 and $28 \mathrm{~d}$ indicated that there were no significant differences between the groups (data not shown), but these did not differentiate between white and gray matter. Furthermore, gross histological assessments of lesion volumes cannot detect alterations in axonal integrity or function. Future experiments assessing spinal cord physiology using electrophysiological techniques as well as retrograde labeling using fluorogold may provide more relevant information.

We note that TIMP-1 is the only endogenous inhibitor of MMPs that is altered early after SCI, indicating that TIMP-2, -3, and -4 are not playing a regulatory role during this time. Furthermore, the expression of TIMP- 1 is highest $24 \mathrm{hr}$ after injury, with mRNA levels increasing 64-fold over uninjured controls and decreasing to 60 - and 34 -fold at $48 \mathrm{hr}$ and $5 \mathrm{~d}$, respectively. Although the expression of TIMP-1 at $5 \mathrm{~d}$ is significantly different from control levels $(p<0.001)$, the fact that levels are decreasing at a time when MMP-12 levels are increasing leads one to postulate that TIMP-1 is not a prominent inhibitor of MMP-12 in this system and that there is an overall increase in proteolytic activity 
after SCI. However, this would need to be proven more formally in future experiments.

Of all the MMPs studied, MMP-10 is most highly upregulated in SCI after MMP-12. Further discussion of this MMP family member seems warranted. Twenty-four hours after injury, mRNA levels were increased 130-fold. MMP-10, also known as stromelysin 2, is capable of degrading various components of the extracellular matrix and basement membrane and has functions in the activation of other pro-MMPs, including pro-MMP-1, -7, -8, and -9 (Nicholson et al., 1989; Windsor et al., 1993; Knauper et al., 1996; Nakamura et al., 1998). The overexpression of MMP-10 has been implicated in corneal pathology in diabetes as well as head, neck, and lung carcinomas (Muller et al., 1991; Saghizadeh et al., 2001). With respect to the CNS, MMP-10 has been found in astrocytomas, spontaneous medulloblastomas, and primitive neuroectodermal tumors (Bodey et al., 2000a,b). The precise role of MMP-10 in all of these cases as well as in SCI remains to be determined.

Although the present work indicates a detrimental role of increased MMP-12 activity in SCI, some of the MMPs expressed after injury may be important for reparative processes (Yong et al., 2001). In normal CNS tissue, MMPs have been implicated in oligodendrocyte process extension (Oh et al., 1999), axonal elongation (Pittman, 1985; Sheffield et al., 1994), and guidance (Webber et al., 2002), as well as the migration of precursor cells through the ECM (Frolichsthal-Schoeller et al., 1999). These actions would also be critical in any processes promoting regeneration and repair of the injured cord. It is likely that some of the other MMPs that are upregulated after SCI may function in this way.

In summary, we have demonstrated high upregulation of MMP-12 in SCI. This metalloproteinase contributes to the secondary injury because, in its absence, mice recovered better from the insult. We attribute the mechanism of MMP-12 pathophysiology to blood-spinal barrier disruption and to the increased frequency and activation of mononuclear phagocytes within the CNS. Other mechanisms, such as a direct role of MMP-12 in producing neurotoxicity, cannot be excluded at this point. Our results suggest that the inhibition of metalloproteinase activity after SCI may facilitate the recovery from this devastating condition.

\section{References}

Arber S, Caroni P (1995) Thrombospondin-4, an extracellular matrix protein expressed in the developing and adult nervous system promotes neurite outgrowth. J Cell Biol 131:1083-1094.

Banda MJ, Werb Z (1981) Mouse macrophage elastase: purification and characterization as a metalloproteinase. Biochem J 193:589.

Basso DM, Beattie MS, Bresnahan JC (1995) A sensitive and reliable locomotor rating scale for open-field testing in rats. J Neurotrauma 12:1-21.

Batchelor PE, Liberatore GT, Wong JYF, Porritt MJ, Frerichs F, Donnan GA, Howells DW (1999) Activated macrophages and microglia induce dopaminergic sprouting in the injured striatum and express brain-derived neurotrophic factor and glial cell line-derived neurotrophic factor. J Neurosci 19:1708-1716.

Blight AR (1983) Cellular morphology of chronic spinal cord injury in the cat: analysis of myelinated axons by line. Neuroscience 10:541-543.

Blight AR (1994) Effects of silica on the outcome from experimental spinal cord injury: implication of macrophages in secondary tissue damage. Neuroscience 60:263-273.

Bodey B, Bodey BJ, Siegel SE, Kaiser HE (2000a) Matrix metalloproteinase expression in childhood astrocytomas. Anticancer Res 20:3287-3292.

Bodey B, Bodey BJ, Siegel SE, Kaiser HE (2000b) Significant differences in the matrix metalloproteinase expression profiles of spontaneous medulloblastomas/primitive neuroectodermal tumors as compared with their xenografted, established tumor cell line derived counterparts. In Vivo 14:675-682.

Chamak B, Morandi V, Mallat M (1994) Brain macrophages stimulate neurite growth and regeneration by secreting thrombospondin. J Neurosci Res 38:221-233.
Curci JA, Liao S, Huffman MD, Shapiro SD, Thompson RW (1998) Expression and localization of macrophage elastase (matrix metalloproteinase12) in abdominal aortic aneurysms. J Clin Invest 102:1900-1910.

D'Haese A, Wuyts A, Dillen C, Dubois B, Billiau A, Heremans H, Van Damme J, Arnold B, Opdenakker G (2000) In vivo neutrophil recruitment by granulocyte chemotactic protein-2 is assisted by gelatinase B/MMP-9 in the mouse. J Interferon Cytokine Res 20:667-674.

Dirnagl U, Iadecola C, Moskowitz MA (1999) Pathobiology of ischaemic stroke: an integrated view. Trends Neurosci 22:391-397.

Dusart I, Schwab ME (1994) Secondary cell death and the inflammatory reaction after dorsal hemisection of the rat spinal cord. Eur J Neurosci 6:712-724.

Egeblad M, Werb Z (2002) New functions for the matrix metalloproteinases in cancer progression. Nat Rev Cancer 2:161-174.

Eidelberg E, Straehley D, Erspamer R, Watkins C (1977) Relationship between residual hindlimb-assisted locomotion and surviving axons after incomplete spinal cord injuries. Exp Neurol 56:312-322.

Fehlings MG, Tator CH (1992) The effect of direct current field polarity on recovery after acute experimental spinal cord injury. Brain Res 579:32-42.

Frolichsthal-Schoeller P, Vescovi AL, Krekoski CA, Murphy G, Edwards DR, Forsyth P (1999) Expression and modulation of matrix metalloproteinase-2 and tissue inhibitors of metalloproteinases in human embryonic CNS stem cells. NeuroReport 10:345-351.

Giulian D, Corpuz M (1993) Microglial secretion products and their impact on the nervous system. Adv Neurol 59:315-320.

Giulian D, Robertson C (1990) Inhibition of mononuclear phagocytes reduces ischemic injury in the spinal cord. Ann Neurol 27:33-42.

Giulian D, Vaca K (1993) Inflammatory glia mediate delayed neuronal damage after ischemia in the central nervous system. Stroke 24:I84-I90.

Giulian D, Corpuz M, Chapman S, Mansouri M, Robertson C (1993) Reactive mononuclear phagocytes release neurotoxins after ischemic and traumatic injury to the central nervous system. J Neurosci Res 36:681-693.

Guth L, Zhang Z, DiProspero NA, Joubin K, Fitch MT (1994) Spinal cord injury in the rat: treatment with bacterial lipopolysaccharide and indomethacin enhances cellular repair and locomotor function. Exp Neurol 126:76-87.

Hartung HP, Kieseier BC (2000) The role of matrix metalloproteinases in autoimmune damage to the central and peripheral nervous system. J Neuroimmunol 107:140-147.

Hautamaki RD, Kobayashi DK, Senior SD, Shapiro SD (1997) Requirement for macrophage elastase for cigarette smoke-induced emphysema in mice. Science 277:2002-2004.

Herx LM, Yong VW (2001) Interleukin-1 beta is required for the early evolution of reactive astrogliosis following CNS lesion. J Neuropathol Exp Neurol 60:961-971.

Herx LM, Rivest S, Yong VW (2000) Central nervous system initiated inflammation and neurotrophism in trauma: IL- $1 \beta$ is required for the production of ciliary neurotrophic factor. J Immunol 165:2232-2239.

Horton MR, Shapiro SD, Bao C, Lowenstein CJ, Noble PW (1999) Induction and regulation of macrophage metalloelastase by hyaluronan fragments in mouse macrophages. J Immunol 162:4171-4176.

Ito D, Imai Y, Ohsawa K, Nakajima K, Fukuuchi Y, Kohsaka S (1998) Microglia-specific localisation of a novel calcium binding protein, Iba1. Brain Res Mol Brain Res 57:1-9.

Johnston JB, Zhang K, Silva C, Shalinsky DR, Conant K, Ni W, Corbett D, Yong VW, Power C (2001) HIV-1 Tat neurotoxicity is prevented by matrix metalloproteinase inhibitors. Ann Neurol 49:230-241.

Jonakait GM, Luskin MB, Wei R, Tian XF, Ni L (1996) Conditioned medium from activated microglia promotes cholinergic differentiation in the basal forebrain in vitro. Dev Biol 177:85-95.

Kim WK, Ko KH (1998) Potentiation of N-methyl-D-aspartate-mediated neurotoxicity by immunostimulated murine microglia. J Neurosci Res 54:17-26.

Knauper V, Murphy G, Tschesche H (1996) Activation of human neutrophil procollagenase by stromelysin 2. Eur J Biochem 235:187-191.

Kreutzberg GW (1996) Microglia: a sensor for pathological events in the CNS. Trends Neurosci 19:312-318.

Lanone S, Zheng T, Liu W, Lee CG, Ma B, Chen Q, Homer RJ, Wang J, Rabach LA, Rabach ME, Shipley JM, Shapiro SD, Senior RM, Elias JA (2002) Overlapping and enzyme-specific contributions of matrix metalloproteinases- 9 and -12 in IL-13-induced inflammation and remodeling. J Clin Invest 110:463-474.

Leong SK, Ling EA (1992) Amoeboid and ramified microglia: their interrelationship and response to brain injury. Glia 6:39-47.

Lo EH, Wang X, Cuzner ML (2002) Extracellular proteolysis in brain injury 
and inflammation: role for plasminogen activators and matrix metalloproteinases. J Neurosci Res 69:1-9.

Mabon PJ, Weaver LC, Dekaban GA (2000) Inhibition of monocyte/macrophage migration to a spinal cord injury site by an antibody to the integrin $\alpha \mathrm{D}$ : a potential new anti-inflammatory treatment. Exp Neurol 166:52-64.

McCawley LJ, Matrisian LM (2001) Matrix metalloproteinases: they're not just for matrix anymore. Curr Opin Cell Biol 13:534-540.

Morioka T, Kalehua AN, Streit WJ (1991) The microglial reaction in the rat dorsal hippocampus following transient forebrain ischemia. J Cereb Blood Flow Metab 11:966-973.

Muller D, Breathnach R, Englemann A, Millon R, Bronner G, Flesch H, Dumont P, Eber M, Abecassis J (1991) Expression of collagenase-related metalloproteinase genes in human lung or head and neck tumours. Int J Cancer 48:550-556.

Nagata A, Takei K, Nakajima K, Saito H, Kohsaka S (1993) Microglial conditioned medium promotes survival and development of cultured mesencephalic neurons from embryonic rat brain. J Neurosci Res 34:357-363.

Nakamura H, Fujii Y, Ohuchi E, Yamamoto E, Okada Y (1998) Activation of the precursor of human stromelysin 2 and its interaction with other matrix metalloproteinases. Eur J Biochem 253:67-75.

Nicholson R, Murphy G, Breathnach R (1989) Human and rat malignanttumor-associated mRNAs encode stromelysin-like metalloproteinases. Biochemistry 28:5195-5203.

Noble LJ, Donovan F, Igarashi T, Goussev S, Werb Z (2002) Matrix metalloproteinases limit functional recovery after spinal cord injury by modulation of early vascular events. J Neurosci 22:7526-7535.

Nuttall RK, Pennington CJ, Taplin J, Wheal A, Yong VW, Forsyth PA, Edwards DR (2003) Elevated membrane-type matrix metalloproteinases in gliomas revealed by profiling proteases and inhibitors in human cancer cells. Mol Cancer Res 1:333-345.

Oh LY, Larsen PH, Krekoski CA, Edwards DR, Donovan F, Werb Z, Yong VW (1999) Matrix metalloproteinase-9/gelatinase B is required for process outgrowth by oligodendrocytes. J Neurosci 19:8464-8475.

O'Shea KS, Liu LH, Dixit VM (1991) Thrombospondin and a 140 kD fragment promote adhesion and neurite outgrowth from embryonic central and peripheral neurons and PC12 cells. Neuron 7:231-237.

Pagenstecher A, Stalder AK, Campbell IL (1997) RNAse protection assays for the simultaneous and semiquantitative analysis of multiple murine matrix metalloproteinase (MMP) and MMP inhibitor mRNAs. J Immunol Methods 206:1-9.

Pittman RN (1985) Release of plasminogen activator and a calciumdependent metalloproteinase from cultured sympathetic and sensory neurons. Dev Biol 110:91-101.

Popovich PG, Guan Z, Wei P, Huitinga I, van Rooijen N, Stokes BT (1999) Depletion of hematogenous macrophages promotes partial hindlimb recovery and neuroanatomical repair after experimental spinal cord injury. Exp Neurol 158:351-365.

Power C, Henry S, Del Bigio MR, Larsen PH, Corbett D, Imai Y, Yong VW, Peeling J (2003) Intracerebral hemorrhage induces macrophage activation and matrix metalloproteinases. Ann Neurol 53:731-742.

Rabchevsky AG, Streit WJ (1997) Grafting of cultured microglial cells into the lesioned spinal cord of adult rats enhances neurite outgrowth. J Neurosci Res 47:34-48.

Rapalino O, Lazarov-Spiegler O, Agranov E, Velan GJ, Yoles E, Fraidakis M, Solomon A, Gepstein R, Katz A, Belkin M, Handani M, Schwartz M (1998) Implantation of stimulated homologous macrophages results in partial recovery of paraplegic rats. Nat Med 4:814-821.
Rogove AD, Tsirka SE (1998) Neurotoxic responses by microglia elicited by excitotoxic injury in the mouse hippocampus. Curr Biol 8:19-25.

Rosenberg GA (2002) Matrix metalloproteinases in neuroinflammation. Glia 39:279-291.

Rostworowski M, Balasingam V, Chabot S, Owens T, Yong VW (1997) Astrogliosis in the neonatal and adult murine brain post-trauma: elevation of inflammatory cytokines and the lack of requirement for endogenous interferon- $\gamma$. J Neurosci 17:3664-3674.

Rothwell NJ, Luheshi G, Toulmond S (1996) Cytokines and their receptors in the central nervous system: physiology, pharmacology, and pathology. Pharmacol Ther 69:85-95.

Saghizadeh M, Brown DJ, Castellon R, Chwa M, Huang GH, Ljubimova JY, Rosenberg S, Spirin KS, Stoilitenko RB, Adachi W, Kinoshita S, Murphy G, Windsor LJ, Kenney MC, Ljubimov AV (2001) Overexpression of matrix metalloproteinase-10 and matrix metalloproteinase- 3 in human diabetic corneas. Am J Pathol 158:723-734.

Shapiro SD, Kobayashi DK, Ley TJ (1993) Cloning and characterization of a unique elastolytic metalloproteinase produced by human alveolar macrophages. J Biol Chem 268:23824-23829.

Sheffield JB, Krasnolpolsky V, Dehlinger E (1994) Inhibition of retinal growth cone activity by specific metalloproteinase inhibitors in vitro. Dev Dyn 200:79-88.

Shipley JM, Wessekschmidt RL, Kobayashi DK, Ley TJ, Shapiro SD (1996) Metalloelastase is required for macrophage-mediated proteolysis and matrix invasion in mice. Proc Natl Acad Sci USA 93:3942-3946.

Streit WJ, Semple-Rowland SL, Hurley SD, Miller RC, Popovich PG, Stokes BT (1998) Cytokine mRNA profiles in contused spinal cord and axotomized facial nucleus suggest a beneficial role for inflammation and gliosis. Exp Neurol 152:74-87.

Vos CM, Sjulson L, Nath A, McArthur JC, Pardo CA, Rothstein J, Conant K (2000) Cytotoxicity by matrix metalloprotease-1 in organotypic spinal cord and dissociated neuronal cultures. Exp Neurol 163:324-330.

Vos CMP, Van Haastert ES, De Groot CJA, Van der Valk P, De Vries HE (2003) Matrix metalloproteinase-12 is expressed in phagocytic macrophages in active multiple sclerosis lesions. J Immunol 138:106-114.

Wang X, Jung J, Asahi M, Chwang W, Russo L, Moskowitz MA, Dixon CE, Fini ME, Lo EH (2000) Effects of matrix metalloproteinase-9 gene knock-out on morphological and motor outcomes after traumatic brain injury. J Neurosci 20:7037-7042.

Webber CA. Hocking JC, Yong VW, Stange CL, McFarlane S (2002) Metalloproteases and guidance of retinal axons in the developing visual system. J Neurosci 22:8091-8100.

Wells JEA, Hurlbert RJ, Fehlings MG, Yong VW (2003) Neuroprotection by minocycline facilitates significant recovery from spinal cord injury in mice. Brain 126:1628-1637.

Windsor LJ, Grenett H, Birkedal-Hansen B, Bodden MK, Engler JA, BirkedalHansen H (1993) Cell type-specific regulation of SL-1 and SL-2 genes: induction of the SL-2 gene but not the SL-1 gene by human keratinocytes in response to cytokines and phorbol esters. J Biol Chem 268:17341-17347.

Yong VW, Power C, Forsyth P, Edwards DR (2001) Metalloproteinases in biology and pathology of the nervous system. Nat Rev Neurosci 2:502-511.

Yrjanheikki J, Keinanen R, Pellikka M, Hokfelt T, Koistinaho J (1998) Tetracyclines inhibit microglial activation and are neuroprotective in global brain ischemia. Proc Natl Acad Sci USA 95:15769-15774.

Yrjanheikki J, Tikka T, Keinanen R, Goldsteins G, Chan PH, Koistinaho J (1999) A tetracycline derivative, minocycline, reduces inflammation and protects against focal cerebral ischemia with a wide therapeutic window. Proc Natl Acad Sci USA 96:13496-13500. 